\title{
Análise das solicitações de assistência técnica - estudo de caso para edificações em residenciais multifamiliares
}

\author{
P.P.B. Pires ${ }^{1}$, F. Pacheco ${ }^{2 *}$, C. Simonetti ${ }^{3}$, H.Z. Ehrenbring ${ }^{4}$, R. Christ $^{5}$ \\ *Autor de Contacto: fernandapache@unisinos.br \\ ${ }^{1}$ Escola Politécnica, Engenharia Civil UNISINOS, São Leopoldo, Brasil \\ 2,3,4,5 Instituto tecnológico em desempenho e construção civil, UNISINOS, São Leopoldo, Brasil
}

\begin{abstract}
RESUMO
É crescente o número de chamados de pós-obra identificando intervenções necessárias para a qualidade plena do imóvel, sendo necessária sua gestão. Nesse estudo analisou-se um banco de dados de assistência técnica de uma construtora, visando classificar e analisar as ocorrências. Objetivou-se a identificação dos sistemas com mais falhas relatadas na fase de uso da edificação, atendimento aos parâmetros de garantia conforme normativas e legislações e o custo de mão de obra para reparo de solicitações de assistência técnica acatadas. Após a análise de 266 solicitações de assistência técnica, contemplando 451 possíveis danos, os resultados apontaram um percentual de $43 \%$ de danos com reparo realizado pela construtora e que os sistemas com maior número de falhas são as instalações e esquadrias.
\end{abstract}

Palavras-chave: assistência técnica; manutenção; intervenção. 


\section{INTRODUÇÃO}

Nos últimos anos, houve um aumento de solicitações de assistência técnica no pós-obra de edificações, intensificado pelo forte crescimento na demanda imobiliária brasileira e justificada por um maior nível de exigência dos consumidores e baixa qualidade das edificações (ALVES; LIRA; JUNIOR, 2019). Conforme a Fundação de Proteção e Defesa do Consumidor de São Paulo (2019), o índice de atendimento das reclamações fundamentadas é insignificante, e isso pode decorrer do fato de as empresas priorizarem a diminuição de custos financeiros.

Todavia, muitas informações podem ser obtidas através das solicitações de assistência técnica, que se bem registradas e analisadas são determinantes na melhoria dos processos construtivos das edificações, diminuição dos custos com o setor de pós-obra e consequentemente maior satisfação dos clientes (CRUZ, 2013). Assim, se corrobora a importância dos pontos citados anteriormente, somado ainda a atual desaceleração do mercado da construção civil, que torna crucial medidas que visam reduzir custos e agregar confiabilidade ao produto final (ARANTES; DE PAULA; BRANDSTETTER, 2016; SIQUEIRA, 2015).

É de fundamental importância que as empresas desenvolvam setores com o foco de atendimento de seus clientes, resolvendo as falhas através da assistência técnica, visando satisfazer o cliente, agregando confiabilidade (SIQUEIRA, 2015).

Conforme Vazquez e Santos (2010), urge a necessidade de implantação e conservação de um sistema de armazenamento de informações, com a finalidade de retroalimentar o processo construtivo de uma edificação, através da descoberta da origem do problema avaliado e decorrente prevenção. Apresentam-se em pesquisas modelos teóricos de organização de dados e procedimentos de melhoria (CUPERTINO; BRANDSTETTER, 2015).

Em termos de normativas nacionais, conta-se com a NBR 15575 (ABNT, 2013), que apresenta parâmetros mínimos das edificações habitacionais, e ainda, desde 2012 com a norma brasileira de manutenção de edificações NBR 5674 (ABNT, 2012), acrescida ainda ao incentivo da busca da qualidade para obtenção de certificações como o PBQP-H (Programa Brasileiro da Qualidade e Produtividade do Habitat) e NBR ISO 9001 (ABNT, 2009). Destaca-se em tais documentos a relevância do cuidado no projeto, execução e cuidado com as edificações.

Os danos identificados na etapa de uso de uma edificação podem causar grande incômodo ao usuário e afetar o desempenho da unidade em questão. Podendo, esses eventos, serem originados pelo mau uso da edificação, o que pode ser caracterizado pela falta da disponibilização do manual de uso, operação e manutenção ou por imperícia do usuário, falhas originadas nas etapas que compõem o processo de produção da edificação, como projeto, aquisição de materiais e execução (ARIVABENE, 2015; CBIC, 2013; HELENE, 1992).

Torna-se necessário que haja, por parte da empresa responsável pela produção da edificação, maior preocupação com os danos encontrados na etapa de uso da edificação, tendo em vista o impacto da satisfação de seus clientes na consolidação da empresa no mercado econômico, e como o registro adequado das informações obtidas através na análise dos danos pode retroalimentar o processo construtivo, agregando maior qualidade ao produto final (SIQUEIRA, 2015; SOUZA; ABIKO, 1997; GIACOMELLI, 2016; TAGUCHI, 2010).

Considerando o cenário apresentado, esse estudo busca avaliar a incidência de chamados de pósobra, ou seja, intervenções após a entrega de imóveis, em um empreendimento com 240 unidades habitacionais de edificação multifamiliar. A análise foi realizada através do banco de dados da empresa construtora, considerando 451 solicitações de assistência técnica para o empreendimento em questão. Os dados foram analisados em termos de local de ocorrências, situação da garantia, distribuição dos danos patológicos por área e origem da falha ou dano. 


\section{A CONSTRUÇÃO CIVIL E A QUALIDADE}

De acordo com Ambrozewicz (2003), o setor da construção civil brasileira é marcado por um grande percentual de trabalhadores com pouca qualificação. A falta de qualificação da mão de obra acaba interferindo na implantação de sistemas de qualidade e produtividade, crucias para o desenvolvimento do setor. A qualidade nas cadeias produtivas da construção civil não ganhou a devida importância por resultado a alta rentabilidade do setor, porém, atualmente a busca pela qualidade é crucial para que se mantenham a competitividade (NETO, 2017).

A gestão da qualidade se tornou um elemento fundamental para as empresas e organizações do setor da construção civil se manterem competitivas no mercado, atendendo a maior exigência dos consumidores quanto a qualidade dos produtos e serviços prestados (ROCHA, 2007; REZENDE, 2013; GOMES, 2003).

Conforme Rezende (2013), é necessário que haja um bom desempenho do produto entregue, satisfazendo os consumidores, com qualidade nos serviços, um bom atendimento, com segurança e credibilidade.

Segundo Vieira e Neto (2019), há dificuldades em se implementar, no setor da construção civil, as ferramentas que compõem a gestão de qualidade e que são utilizadas em outros setores industriais, e isso acontece porque a cadeia produtiva encontrada no setor é diferenciada. São poucas as obras que possuem um processo produtivo repetitivo, criando certa dificuldade em se padronizar a cadeia produtiva privando-a de uma série de benefícios como a padronização, optimização do tempo, diminuição de erros e consequente redução de retrabalho, diminuição de custos, que resultam consequente em mais qualidade no produto final.

Para que se tenha efetividade na implantação de um sistema de qualidade em uma empresa, o mesmo deve atuar em todos os setores que compõem a mesma, deste o setor de produção aos recursos humanos. A partir de um conjunto de técnicas interligadas entre si, geram maior organização, e consequente maior competitividade, possibilitando que se alcance o obtivo final que é satisfação de seus clientes (AMBROZEWICZ, 2003).

Um incentivo para as empresas surgiu com a norma de desempenho, que traz requisitos mínimos de desempenho e tornaram-se o objetivo das construtoras e demais empresas prestadoras de serviço que compõem o setor da construção civil brasileira (SOUZA, 2016).

\subsection{Assistência técnica}

A assistência técnica é uma das funções do setor de atendimento ao consumidor de uma empresa, destina a clientes que identificaram falhas no produto que lhe foi entregue, visando sua satisfação e uma repercussão favorável da empresa no mercado (SIQUEIRA, 2015). Assim, é imprescindível que seja bem estruturado, com um banco de dados e uma análise, se a solicitação é procedente ou não. Caso procedente, ou seja, dentro dos prazos e requisitos de garantia, é dado andamento a assistência, sendo posteriormente agendado uma vistoria na unidade do solicitante.

Siqueira (2015) informa sobre os cuidados as vistorias e o fechamento da solicitação técnica, coletando a assinatura do cliente, comprovando a solicitação e aceitação da solução adotada. Vale destacar que é crucial a verificação da satisfação do cliente quanto ao atendimento, desde a qualidade do serviço à conduta da equipe (SIQUEIRA, 2015; SOUZA; ABIKO, 1997).

Segundo Souza e Abiko (1997), outra função da assistência técnica é retroalimentar o processo produtivo da empresa, e isso ocorre por meio do registro das informações obtidas a cada solicitação, fundamentando a melhoria contínua e mitigando os erros.

\subsection{Manual do usuário}

Trata-se do canal de instruções técnicas das empresas aos usuários, visando que suas intervenções no imóvel sejam realizadas de modo satisfatório. Segundo Michelin (2005), o Manual de Uso, 
Operação e Manutenção das edificações, é de suma importância, pois é o responsável pela interação entre as etapas de construtivas e de uso. Além de definir quais são os deveres do construtor e usuário, evita que a empresa seja responsabilizada pelo má utilização ou má fé do usuário, sendo sua justificativa a explicação de como proceder quanto sua utilização e manutenção.

\subsection{Aspectos jurídicos}

A finalidade do Código de Defesa do Consumidor (CDC) é igualar a relação entre o consumidor e o fornecedor. Essa relação se enquadra na construção civil, onde se tem o consumidor e o fornecedor (MEIRELLES, 2005; PELACANI, 2010).

$\mathrm{O}$ CDC faz a diferenciação entre vícios e defeitos encontrados em uma edificação na etapa de uso. O vício interfere na plenitude da edificação, decrescendo seu valor. Já o defeito é considerado um vício de maior gravidade, o qual pode colocar em risco a segurança do usuário, seus bens ou terceiros (MEIRELLES, 2005). Ainda, conforme o CDC, os defeitos encontrados em uma edificação são de responsabilidade do fornecedor, ou seja, em caso de danos o mesmo deverá ressarcir, independe de culpa, o consumidor e vítimas do evento, explicitado nos artigos 12 e 14 . Já nos casos de vícios construtivos, o fornecedor só responderá caso for comprovado a sua culpa no evento (MEIRELLES, 2005).

Os vícios são considerados falhas que o imóvel possa apresentar que tornam seu uso impróprio ou que possam acarretar a desvalorização do mesmo. São casos em que o produto não apresenta a qualidade ou quantidade adquirida. Os defeitos são considerados falhas que possam pôr em risco a saúde e segurança do usuário. Ambos podem ser divididos entre aparentes e ocultos, os parentes são de fácil constatação e podem ser identificados no momento na compra ou entrega das chaves, já os ocultos normalmente só são identificados durante o uso da edificação (BARROS FILHO; RIVELINI, 2016).

\subsection{Manifestações patológicas}

Conforme Giacomelli (2016) e Taguchi (2010), o estudo das manifestações patológicas é crucial para a construção civil, principalmente pela grande quantidade de informações que podem ser obtidas em tal análise, como já falado, visando a melhoria contínua, através da retroalimentação de seus processos construtivos (FIESS et al., 2004).

Muitos fatores podem influenciar na deterioração antecipada das edificações, desde a erros de projeto, falhas construtivas, má utilização, matérias empregados de maneira incorreta, falhas involuntárias envelhecimento natural (ARIVABENE, 2015).

Conforme Helene (1992), o processo construtivo de uma edificação é composto pelas etapas de planejamento, projeto, fabricação dos materiais, execução e uso, sendo essas as possíveis origens das falhas. Segundo Arivabene (2015) e Helene (1992), as manifestações patológicas geradas através de erros de projeto são os mais preocupantes, principalmente devido a sua grande incidência e gravidade acentuada quando comparadas a manifestações ocasionadas por falhas construtivas ou qualidade de materiais.

A falta de compatibilização dos projetos acaba gerando problemas complicados, de resolução dificultada. Vale destacar também a falha na escolha por materiais adequados. Outro problema detectado são erros de cálculos estrutural, principalmente na definição dos esforços atuantes sobre a edificação, inexistentes ou escassez de juntas de dilatação, poucos estudos a respeito do solo onde será construído a edificação, início da etapa de execução antes da conclusão da etapa de projeto (ARANTES; DE PAULA; BRANDSTETTER, 2016; ARNALDO, 2007).

No cenário das falhas, tem-se ainda as de origem nos materiais, conforme Fiess (2004), identificadas por deterioração dos materiais, isentos da influência das etapas de projeto e execução. Salermo (2005) destaca que a maioria das manifestações patológicas geradas por falhas de 
materiais são identificadas apenas na etapa de uso da edificação e são resultado da escolha de materiais de baixa qualidade, onde o fator custo predominou na escolha do mesmo.

É somente na fase de execução que as manifestações patológicas começam a surgir, ou seja na última etapa do processo construtivo, e surgem em maior número na etapa de uso. $\mathrm{O}$ que cria a necessidade de que se faça um diagnóstico preciso, visando identificar a etapa onde surgiu o problema (HELENE, 1992).

Boa parte das manifestações patológicas geradas na etapa de execução são devido a utilização de mão de obra mal qualificada. Além disso, ainda pode ocorrer a utilização inadequada dos materiais de construção, (ARANTES; DE PAULA; BRANDSTETTER, 2016; FIESS et al., 2004; ARNALDO, 2007; TAGUCHI, 2010). A falta de conhecimento técnico ligado ao uso e manutenibilidade das edificações, problemas econômicos e incompetência, sãos os principais responsáveis por manifestações patológicas ocasionadas por uso inadequado, manutenção incorreta ou falta de manutenção (ARIVABENE, 2015). As falhas de uso por muitas vezes ocorrem em decorrência do não entendimento dos usuários leigos sobre as características de manutenção pertinentes em uma edificação e pela carência de tais tarefas por parte das construtoras, com instrumentos como manual de uso, operação e manutenção, já citado.

\section{PROCEDIMIENTO}

\subsection{Estudo de caso}

O banco de dados de registros de solicitações de assistência técnica analisado pertence a uma empresa construtora. A empresa produz empreendimentos habitacionais multifamiliares, sendo o padrão construtivo predominante adotado para as edificações produzidas pela empresa enquadrado no programa do Governo Brasileiro Minha Casa Minha Vida (MCMV) como Faixa 3. A empresa executa também edificações com padrão construtivo médio superior.

De acordo com o efetivo de mão de obra disponível, e em consoante com a política da empresa, há sempre duas edificações na fase produção em andamento, tendo pelo menos uma terceira na fase de planejamento e de projeto.

A construtora conta com 5 empreendimentos já entregues, todos eles de edificações multifamiliares. No quadro da empresa há um profissional responsável por atuar na assistência técnica, sendo responsável pelo atendimento ao público externo na solução de intervenções necessárias nas edificações, sendo assim uma estrutura enxuta de pós-obra.

\subsubsection{Empreendimento e sistema construtivo}

O sistema construtivo utilizado é o de alvenaria estrutural. O empreendimento em estudo foi o Moradas de Sapucaia, foi entregue em 3 fases (etapas), sendo dividida em 80 apartamento por fase. A primeira fase foi entregue dia 4 de abril de 2019, a segunda foi dia 10 de dezembro de 2019 e por fim, a terceira fase foi entregue em fevereiro de 2020.

\subsubsection{Documentação referente à qualidade e ao controle da empresa}

Foram analisados os documentos disponibilizados pela empresa em relação a sua aplicação, pertinência e profissionais envolvidos.

a) Entrega das chaves: a empresa adota o documento de recebimento de unidade. Nesse documento o cliente atesta o recebimento do imóvel, estando em conformidade com a vistoria do momento da entrega, através de sua leitura e assinatura. Além disso, ele assinala o recebimento de documentos, como manual de uso, operação e manutenção, chaves, entre outros. E também, ele se responsabiliza pelo repasse desse manual caso a unidade seja vendida. 
b) Abertura de chamado de atendimento: Há algum tempo a construtora desenvolveu uma ficha padrão, na qual se descreve o problema, classificando entre serviço técnico ou não técnico, assim como, a situação da garantia.

Para realização desse estudo, ampliou-se a análise dos dados, de acordo com os itens apresentados na Tabela 1.

Tabela 1. Classificação das ocorrências patológicas.

\begin{tabular}{|c|c|c|c|c|c|c|}
\hline $\mathbf{A}$ & B & $\bar{C}$ & D & $\mathbf{E}$ & $\mathbf{F}$ & $\bar{G}$ \\
\hline $\begin{array}{l}\text { Empreendi- } \\
\text { mento }\end{array}$ & $\begin{array}{c}\text { Tipo de } \\
\text { Ocorrência }\end{array}$ & $\begin{array}{c}\mathrm{N}^{\mathrm{o}} \\
\text { Ocorrência }\end{array}$ & $\begin{array}{c}\text { Status / } \\
\text { ocorrência }\end{array}$ & Local / Apto & Data & Sistema \\
\hline $\mathbf{H}$ & I & $\mathbf{J}$ & $\mathbf{K}$ & $\mathbf{L}$ & $\mathbf{M}$ & $\mathbf{N}$ \\
\hline $\begin{array}{c}\text { Solicitação } \\
\text { Cliente }\end{array}$ & $\begin{array}{l}\text { Data/Hora } \\
\text { da Vistoria }\end{array}$ & $\begin{array}{c}\text { Análise da } \\
\text { Vistoria }\end{array}$ & $\begin{array}{l}\text { Origem da } \\
\text { Falha }\end{array}$ & Código & $\begin{array}{c}\text { Data de } \\
\text { Entrega } \\
(\text { Anos) }\end{array}$ & $\begin{array}{c}\text { Tempo de } \\
\text { uso } \\
\text { (Anos) } \\
\end{array}$ \\
\hline $\mathbf{O}$ & $\mathbf{P}$ & $\mathbf{Q}$ & $\mathbf{R}$ & $\mathbf{S}$ & $\mathbf{T}$ & $\mathbf{U}$ \\
\hline $\begin{array}{c}\text { Garantia } \\
\text { item }\end{array}$ & $\begin{array}{l}\text { Prazo de } \\
\text { garantia }\end{array}$ & Profissional & $\begin{array}{l}\text { Data/Hora } \\
\text { do Serviço }\end{array}$ & $\begin{array}{c}\text { Data de } \\
\text { Fechamento }\end{array}$ & $\begin{array}{c}\text { Prazo de } \\
\text { atend. }\end{array}$ & $\begin{array}{l}\text { Mão de } \\
\text { Obra (h) }\end{array}$ \\
\hline $\mathbf{V}$ & & & & & & \\
\hline $\begin{array}{l}\text { Ok do } \\
\text { cliente }\end{array}$ & & & & & & \\
\hline
\end{tabular}

Na coluna A identifica-se o empreendimento. Na coluna B, destaca-se se é uma ocorrência em área comum ou privativa. Na coluna $\mathrm{C}$ segue-se uma sequência numeral. A coluna $\mathrm{D}$ aponta o status da ocorrência. As colunas E e F apresentam as informações de local e datal, respectivamente. A coluna $\mathrm{G}$ tem função importante, indicando em que sistema ocorreu o ano, como esquadrias ou revestimento. A coluna $\mathrm{H}$ é alusivo a uma acolhida às solicitações do cliente. $\mathrm{O}$ item I apresenta os dados da vistoria. O item $\mathrm{J}$ descreve-se o dano. No item $\mathrm{K}$ busca-se atribuir uma origem a uma falha verificada. $\mathrm{O}$ item $\mathrm{L}$ é referente a um código de identificação. Os itens $\mathrm{M}$ e $\mathrm{N}$ envolvem a data de entrega e o tempo de uso da edificação, respectivamente. Analisando esses dois pontos, preenche-se o item $\mathrm{O}$, indicando se há garantia no item e se houver, no item $\mathrm{P}$ preenche-se o prazo. No item Q, indica-se o profissional necessário para o reparo. Os itens R, S e T, indicam a data do serviço, de fechamento e o prazo para o atendimento. Apontam-se nos itens finais a quantidade de horas para o serviço e a satisfação ou não do cliente.

\section{RESULTADOS}

Ao analisar o local de ocorrência, por exemplo, tem-se 93 ocorrências nas áreas comuns, em relação a 358 localizadas nas unidades, em área privativa. A Figura 1a apresenta graficamente essa ocorrência. 
Local de ocorrência dano/falha

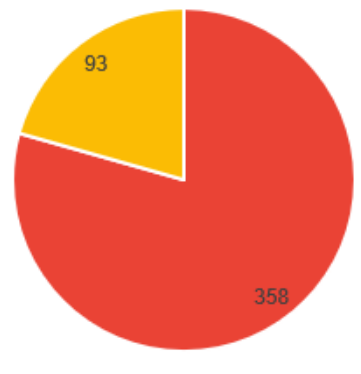

- Área Privada = Área Comum
Situação em relação a garantia

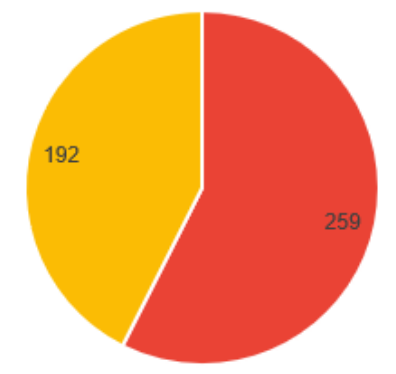

- Fora de Garantia - Dentro da Garantia

Figura 1. Local de ocorrências do dano/falha (a) e situação em relação a garantia (b).

Percebe-se assim, que grande parte dos danos patológicos é percebido no interior das unidades habitacionais. Ao analisar a origem desses danos, pode-se atribuir a maior presença no interior em decorrência dos sistemas empregados. Sabe-se que, conforme Antunes (2010), um dos itens de maior ocorrência patológica é o revestimento cerâmico, aplicado nas áreas molháveis, o que não ocorre nas áreas comuns (circulação), e assim, seu registro se dá nas unidades.

Checinel et al (2009) destacam ainda os danos patológicos que decorrem de instalações e projetos complementares, e assim, pode-se também perceber que essa incidência tende a ocorrer no interior dos imóveis, justificando esse percentual de $79 \%$ dentre as manifestações percebidas no presente estudo.

Conforme apresenta a Figura 1b, dos 451 apontamentos presentes nas 266 solicitações de assistência técnica analisadas constatou-se que 259 delas enquadravam-se como fora de garantia, sendo estes critérios balizados pelo Manual de Uso, Manutenção e Operação entregue junto a unidade.

Lima (2015) observou que, em edificação residencial sem rotina de manutenção implementada, danos ocorrem apenas em casos críticos que já apresentavam perda de desempenho. Fato que pode estar relacionado com o apresentado na Figura 1b, pois sem a realização de manutenção podem não ter sido identificados sintomas iniciais, que podem ter surgido ainda no período da garantia do imóvel, o que alteraria o cenário verificado.

De acordo com Mello (2010), o Código Civil estabelece que os vícios aparentes são de consciência do proprietário da unidade no momento de seu recebimento, ou seja, itens enquadrados como danos aparentes não possuem garantia legal. Conforme graficamente na Figura 1, grande parte dos danos relatos pelos clientes após o recebimento da unidade, são classificados como aparentes e sem garantia, sendo uma possível justificativa para o maior número de solicitações com este enquadramento.

Mello (2010) ressalta que como não há a definição por parte do Código Civil e Código de Defesa do Consumidor as normativas da ABNT, especificamente a NBR 15575 (ABNT, 2013), deve servir como parâmetro para determinação dos prazos de garantia mínimos, sendo esses requisitos base para elaboração dos critérios de garantia utilizados pela construtora e na planilha desenvolvida neste presente trabalho.

Conforme a Tabela 2, onde estão compilados os 8 sistemas com o maior número de danos registrados, tem-se que englobam 76,5\% registros realizados. Sendo as Instalações Elétricas, como pode ser observado na Figura 2, o sistema com o maior número de danos e falhas. 
Tabela 1. Principais sistemas com danos/falhas relatadas.

\begin{tabular}{|l|l|}
\hline $\begin{array}{l}\text { Instalações elétricas - tomadas/interruptores/disjuntores/fios/ cabos/eletrodutos /caixas e } \\
\text { quadros }\end{array}$ & 125 \\
\hline $\begin{array}{l}\text { Instalações hidráulicas coletores/ramais/ louças/caixas de descarga/bancadas/metais } \\
\text { sanitários/ sifões/ ligações flexíveis/ válvulas/registros/ ralos/tanques }\end{array}$ & 25 \\
\hline Esquadrias de alumínio e persianas de PVC & 60 \\
\hline Esquadrias de madeira & 31 \\
\hline $\begin{array}{l}\text { Revestimentos de paredes, pisos e tetos internos e externos em argamassa/ componentes } \\
\text { de gesso acartonado }\end{array}$ & 23 \\
\hline Revestimentos de paredes, pisos e tetos em azulejo/ cerâmica & 35 \\
\hline Pintura/verniz (interna/externa) & 11 \\
\hline $\begin{array}{l}\text { Equipamentos industrializados (motobombas, filtros, interfone, automação de portões e e } \\
\text { outros). Sistemas de interfonia }\end{array}$ & 35 \\
\hline
\end{tabular}

\section{Distribuição dos danos patológicos por área}
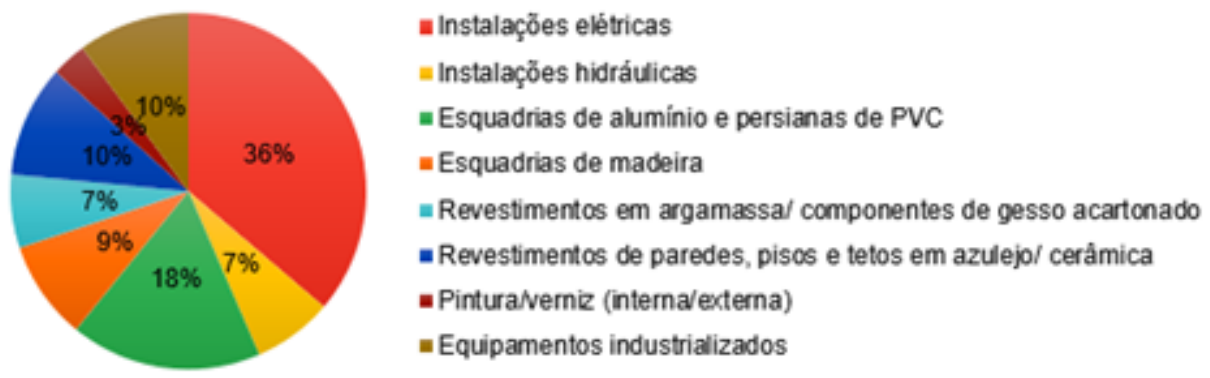

Figura 2. Distribuição dos danos patológicos por área.

Os resultado evidenciados na Tabela 2 e na Figura 2 são semelhantes ao encontrado por Tejo (2018), onde o mesmo informou que as instalações elétricas foram o sistema com maior número de registros de solicitação de assistência técnica, aproximadamente 21,31\%.

Com base nas descrições relatadas após a vistoria realizada na unidade reclamante, consta-se que grande incidência dos problemas identificados possui origem relaciona a execução e qualidade dos materiais empregados na execução do empreendimento.

Medeiros (2004) analisando um banco de dados de diversas edificações habitacionais, percebeu que os danos patológicos foram percebidos principalmente nos revestimentos, coberturas, paredes de vedação e instalações dos imóveis. Em relação aos dados do presente estudo, percebe-se semelhança, pois as instalações e o fechamento também ocorreram de modo predominante.

Rodrigues (2013) além de concordar com os resultados em termos dos principais sistemas com danos, destacou um percentual de 35\% para as instalações elétricas e hidráulicas com danos apresentados, valor próximo ao resultado obtido na presente pesquisa. No estudo realizado por Prates et al (2019), onde os mesmos determinaram que os revestimentos em geral fazem parte dos 3 principais sistemas com falhas registradas, novamente denota-se semelhança com os resultados obtidos na pesquisa e apresentados na Figura 2.

Como pode ser observado na Figura 3, foi realizada a classificação em relação a origem da falha ocasionada e identificada na fase de uso da edificação, tal informação é de extrema importância para mensuração do impacto financeiro causado pela falha e mapeamento para tomada de ação visando mitigação ou eliminação de sua ocorrência. 


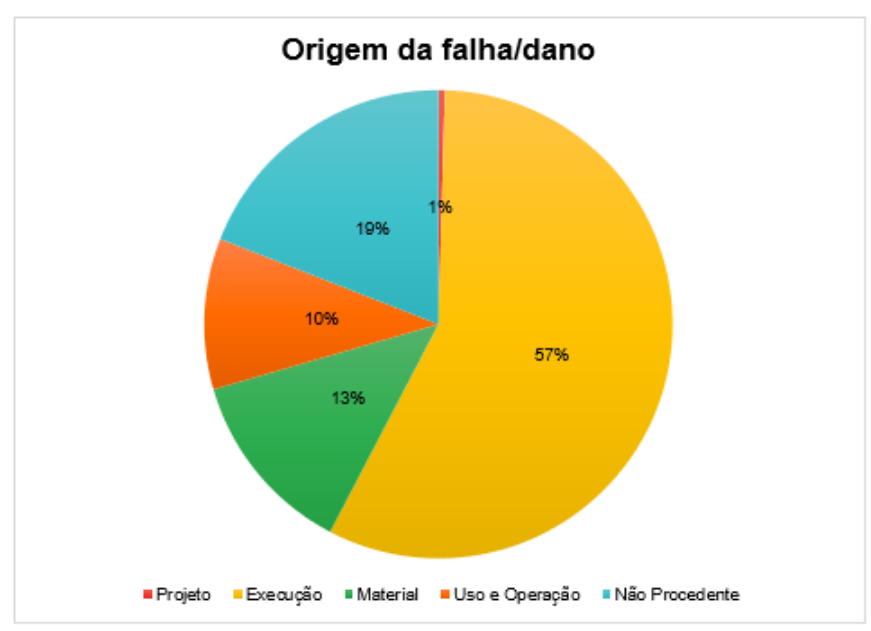

Figura 3. Origem da falha/dano.

Através da representação gráfica, pode se observar um grande percentual de falhas com origem na fase de execução do processo construtivo, sendo muitos deles advindos da falta de treinamento da mão de obra, falta de controle de qualidade e conferência. Vale destacar que atividades executadas antes do momento ideal, por exemplo revestimentos cerâmicos, tendo sido percebido no decorrer do processo que a mesma ocorreu na construção alvo do estudo realizado, resultou em um grande fluxo de pessoas e equipamentos após o assentamento das peças, aumento a incidências de danos. Vale destacar que o uso de materiais de baixa qualidade resultaram em ações interventivas e transtornos aos usuários das unidades habitacionais, serve como exemplo as esquadrias de alumínio e disjuntores. Ocorreu um número significante de falhas ocasionas pelo uso incorreto dos equipamentos e sistemas que compõem a edificação, muitos ocasionados pela falta de verificação/leitura do Manual de Uso, Operação e Manutenção, onde há especificação de materiais e práticas a serem adotadas nas unidades. Como por exemplo, o uso de eletrodomésticos incompatíveis com o dispositivo residual de proteção, o qual é contra indicado e mesmo assim tiveram grande incidência de uso.

No estudo realizado por Cupertino e Brandstetter (2015), no qual os mesmos realizaram o mapeamento da origem das falhas/danos registrados, estimou-se que $44 \%$ eram advindos da fase de execução e $22 \%$ dos materiais empregados. Já no estudo realizado por Siqueira (2015), constatou-se que $77 \%$ das falhas tiverem origem na fase de execução e $26 \%$ dos materiais utilizados. Valores bastante próximos e proporcionais aos encontrados na presente pesquisa, sendo eles $57 \%$ originados na execução e $13 \%$ dos materiais.

No Tabela 3 está representado os sistemas com maior número de horas de mão de obra geradas em decorrência de assistências técnicas.

Tabela 2. Sistemas com maior número de horas de mão de obra geradas em decorrência de assistências técnicas.

\begin{tabular}{|c|c|}
\hline Sistemas & Horas \\
\hline Instalações elétricas & 101,6 \\
\hline Instalações hidráulicas & 23,0 \\
\hline Esquadrias de alumínio e persianas de PVC & 64,0 \\
\hline Esquadrias de madeira & 23,0 \\
\hline Revestimentos em argamassa/ componentes de gesso acartonado & 34,0 \\
\hline Revestimentos de paredes, pisos e tetos em azulejo/ cerâmica & 24,0 \\
\hline Equipamentos industrializados & 22,5 \\
\hline
\end{tabular}


De acordo com a Tabela 3, as instalações elétricas formam o sistema com maior quantidade de horas em comparação aos demais sistemas. Tal comportamento foi observado também na pesquisa realizado por Cupertino e Brandstetter (2015), onde os mesmo estimaram que as instalações elétricas foram responsáveis por $21,09 \%$ do custo total gerado através do atendimento de solicitações de assistência técnica. O custo gerado pelos reparos realizados após a entrega das unidades, ou seja, através do serviço de atendimento ao cliente, é um indicador bastante utilizado pela construtora, como foi observado no estudo realizado por Alves et al (2019), onde os autores estimaram que $50 \%$ das construtoras avaliadas fazem uso do indicador.

\section{CONCLUSÃO}

Tendo em vista que o objetivo principal da presente pesquisa era analisar a gestão para o registro de solicitações de assistência técnica de uma construtora específica, conclui-se que o objetivo foi atingido e por meio da avaliação do banco de dados físico dos registros de solicitações técnicas, foi possível desenvolver uma planilha eletrônica contemplando os principais parâmetros necessários e de impacto relevante para obtenção dos indicadores visados. Pode-se afirmar que o setor de pós-obra é uma fonte indispensável para aperfeiçoamento das etapas que constituem a construção de uma edificação.

Com base na avaliação de 266 registros de solicitações de assistência técnica de uma construtora de porte médio, totalizando mais de 451 apontamentos, foi possível identificar os principais sistemas com danos relatados, e com base nesses sistemas determinar os que mais necessitam intervenção nas etapas que antecedem seu uso. Sendo possível assim aprimorar os processos construtivos, permitindo a melhoria contínua e desenvolvimento. Resultando em um produto com maior qualidade, desempenho e satisfação do cliente.

Objetivou-se nesse estudo a análise das características das solicitações registradas, observou-se que mais de $57 \%$ do danos relatados não foram cobertos pela garantia, por mais que tal percentual induza a interpretação de que houve economia pelo número menor de assistências prestadas, e que houve o atendimento as normativas e legislações no que tange os direitos do consumidor, denotase grande incidências de danos que não só interferem na qualidade produto final, como também tem influência determinante na satisfação do cliente.

A quantificação do custo de mão de obra é de suma importância para mensuração do quão ocioso torna-se os reparos realizados após a entrega da unidade. O mesmo pode ser obtido para cada solicitação e para cada sistema que compõem a edificação através da planilha gerada no estudo, sendo assim é permito afirmar que o objetivo específico foi atendido com satisfação e torna-se viável fazer o comparativo entre o custo de uma ação interventiva ou preventiva com este indicador em questão.

O presente estudo caso tem sua justificativa comprovada no que tange a necessidade de maior aproveitamento das informações provenientes da fase de uso das edificações, corroborada pela necessidade crescente da busca pela satisfação do cliente final, ansiando não só pelo atendimento as legislações protetivas do consumidor cada vez mais complexas, mas por gerar um produto final com maior qualidade e desempenho, proporcionando o desenvolvimento do setor da construção civil.

\section{REFERÊNCIAS}

ALVES, K. C. C.; LIRA, V. Q.; JUNIOR, A. C. L. O pós-obra em empresas da construção civil. Revista de Engenharia Civil, v. 12, n. 56, p. 34-43, 2019.

AMBROZEWICZ, P. H. L. Metodologia para capacitação e implantação de sistema de gestão da qualidade em escala nacional para profissionais e construtoras baseado no PBQP-H e em Educação 
à Distância. 2003. Tese (Doutorado em Engenharia de Produção) - Universidade Federal de Santa Catarina, Florianópolis, 2003.

Antunes, G. R. Estudo de manifestações patológicas em revestimento de fachada em Brasília sistematização da incidência de casos. Dissertação (Mestrado) - Departamento de Engenharia Civil e Ambiental, Universidade de Brasília, Brasília, 2010.

ARANTES, G. M.; DE PAULA, R. F.; BRANDSTETTER, M. C. G. O. Subsídios para o gerenciamento de risco na Construção Civil - Probabilidade e análise no pós obra. In: XXXVI Encontro Nacional de Engenharia de Producão, 2016. Anais [...]. João Pessoa: Associação Brasileira de Engenharia de Produção, 2016.

ARIVABENE, A. C. Patologias em Estruturas de Concreto Armado - Estudo de Caso. Revista Especialize On-line IPOG, v. 01, p. 1-22, 2015.

ARNALDO, M. E. A. 20 Anos na Construção Civil. In: Encontro de 20 anos da Engenharia Civil, 2007. Anais [...]. Portugal, Tomar: Instituto Politécnico de Tomar - Departamento de Engenharia Civil, 2007.

ASSOCIAÇÃO BRASILEIRA DE NORMAS TÉCNICAS (ABNT). ISO 9001: Sistemas de gestão da qualidade - Requisitos. Rio de Janeiro: ABNT, 2015.

ASSOCIAÇÃO BRASILEIRA DE NORMAS TÉCNICAS (ABNT). NBR 15575: Edificações habitacionais: Desempenho. Rio de Janeiro: ABNT, 2013.

ASSOCIAÇÃO BRASILEIRA DE NORMAS TÉCNICAS (ABNT). NBR 5674: Manutenção de edificações - Requisitos para o sistema de gestão de manutenção. Rio de Janeiro: ABNT, 2012.

BARROS FILHO, O. X. de; RIVELINI, A. R. B. Vícios construtivos em obras públicas: um estudo de caso em 27 obras. Revista UNINGÁ Review, v. 28, n.2, p.16-23, 2016.

CÂMARA BRASILEIRA DA INDÚSTRIA DA CONSTRUÇÃO (CBIC). Guia nacional para a elaboração do manual de uso, operação e manutenção das edificações. Fortaleza: Gadioli Cipolla Branding e Comunicação, 2014.

CECHINEL, B. M.; VIEIRA, F. L.; MANTELLI, P.; TONEL, S. O. Infiltração em alvenaria estudo de caso em edifício na Grande Florianópolis. Caderno de Publicações Acadêmicas, v. 1, n. 1, p. 18-24, 2009.

CRUZ, D. C. Análise de solicitações de assistência técnica em empreendimentos residenciais como ferramenta de gestão. 2013. Dissertação (Mestrado em Geotecnia, Estruturas e Construção Civil) Universidade Federal de Goiás, Goiânia, 2013.

CUPERTINO, D.; BRANDSTETTER, M. C. G. O. Proposição de ferramenta de gestão pós obra a partir dos registros de solicitação de assistência. Revista Ambiente Construído, v. 15, n. 4, p. 243 265, out./dez. 2015. doi: 10.1590/s1678-86212015000400049

FIESS, J. R. F. et al. Causas da ocorrência de manifestações patológicas em conjuntos habitacionais do estado de São Paulo. In: Encontro Nacional de Tecnologia do Ambiente Construído, 2004. Anais [...]. São Paulo: Associação Nacional de Tecnologia do Ambiente Construído, 2004.

FUNDAÇÃO DE PROTEÇÃO E DEFESA DO CONSUMIDOR DE SÃO PAULO (PROCONSP). Cadastro de reclamações fundamentadas - 2018. São Paulo: PROCON-SP, 2019.

GIACOMELLI, D. V. Principais patologias encontradas nos prédios da UFSM executados pelo Programa REUNI. 2016. Dissertação (Mestrado) - Universidade Federal de Santa Maria, Santa Maria, 2016.

GOMES, A. Metodologia para implantação do PBQP-H em empresas construtoras no Noroeste Fluminense: um estudo de caso. In: XXIII Encontro Nac. de Eng. de Produção, 2003. Anais [...]. Ouro Preto: Associação Brasileira de Engenharia de Produção, 2003.

HELENE, P. R. L. Manutenção para reparo, reforço e proteção de estruturas de concreto. $2^{\mathrm{a}}$ ed. São Paulo: PINI, 1992.

LIMA, B. S. Principais manifestações patológicas em edificações multifamiliares. 2015. Trabalho de conclusão de curso (Graduação) - Curso de Engenharia Civil, Centro de Tecnologia, 
Universidade Federal de Santa Maria, Santa Maria, 2015.

MEDEIROS, V. Q. Análise e mapeamento das manifestações patológicas vistoriadas pela seguradora em imóveis financiados pela Caixa Econômica Federal no Rio Grande do Sul em 1999 e 2000. 2004. Dissertação (Mestrado) - Universidade Federal do Rio Grande do Sul, Porto Alegre, 2004.

MEIRELLES, H. L. Direito de construir. 9a ed. São Paulo: Malheiros, 2005.

MELLO, G. Q. Responsabilidades e garantias na Construção Civil. 2010. Dissertação (Mestrado) - Universidade do Vale do Itajaí, Itajaí, 2010.

MICHELIN, L. A. C. Manual de operação, uso e manutenção das edificações residenciais multifamiliares: coleta e avaliação de exemplares de empresas de Caxias do Sul-RS. 2005. Dissertação (Mestrado) - Universidade Federal do Rio Grande do Sul, Porto Alegre, 2005.

NETO, M. L. M. A utilização da norma ISO 9001 na Indústria da Construção. 2017. Dissertação (Mestrado) - Faculdade de Engenharia da Universidade do Porto, Porto, 2017.

PELACANI, V. L. Responsabilidade na construção civil. Curitiba: Caderno do Conselho Regional de Engenharia e Agronomia do Paraná, 2010.

PRATES, A. E.; NASCIMENTO, J. C.; MENDES, K. E. Principais manifestações patológicas em conjunto habitacional de interesse social - Montes Claros/MG. Revista Intercâmbio, v. 15, p. 1434, 2019.

REZENDE, J. L. Processo de Implementação do PBQP-h: O Caso dos Municípios Paranaenses. 2013. Dissertação (Mestrado) - Universidade Federal de Santa Maria, Santa Maria, 2013.

ROCHA, M. Q. B. Elaboração de indicadores e uso de ferramentas de controle da qualidade na execução de obras prediais. 2007. Dissertação (Mestrado em Engenharia Civil) - Universidade Estadual do Rio de Janeiro, Rio de Janeiro, 2007.

RODRIGUES, A. C. Levantamento das principais manifestações patológicas em edificações residenciais de uma construtora de Porto Alegre. 2013. Dissertação (Mestrado) - Universidade Federal do Rio Grande do Sul, Porto Alegre, 2013.

SALERMO, L. S. Aplicação de ferramentas da mentalidade enxuta e da manutenção autônoma aos serviços de manutenção dos sistemas prediais de água. 2005. Dissertação (Mestrado) Universidade Estadual de Campinas, Campinas, 2005.

SIQUEIRA, T. D. Assistência técnica na construção de edifícios. Revista Especialize On-line IPOG, v. 01, p. 1-22, 2015.

SOUZA, J. L. P. Desafios na implantação do nível superior da norma de desempenho em edificação residencial em Novo Hamburgo/RS. 2016. Dissertação (Mestrado) - Programa de Pós-graduação em Engenharia Civil, Universidade do Vale do Rio dos Sinos, São Leopoldo, 2016.

SOUZA, R. de. Metodologia para desenvolvimento e implantação de sistemas de gestão da qualidade em empresas construtoras de pequeno e médio porte. 1997. Tese (Doutorado) Universidade de São Paulo, São Paulo, 1997.

TAGUCHI, M. K. Avaliação e qualificação das patologias das alvenarias. 2010. Dissertação (Mestrado) - Universidade Federal do Paraná, Curitiba, 2010.

TEJO, F. A. C. Análise das principais patologias pós-obra por um setor de assistência técnica de uma construtora de pequeno porte. 2018. Dissertação (Mestrado) - Universidade Federal do Rio de Janeiro, Rio de Janeiro, 2018.

VAZQUEZ, E. G.; SANTOS, V. Estudo estatístico de patologia na pós-entrega de empreendimentos imobiliários. In: Encontro Nacional de Tecnologia do Ambiente Construído, v. $13,2010$.

VIEIRA, E. S.; DE OLIVEIRA NETO, J. M. Qualidade na Construção Civil: PBQP-H-Análise do Programa Brasileiro de Qualidade e Produtividade do Habitat. Revista ETIS, Journal of Engineering, Technology, Innovation and Sustainability, v. 1, n. 1, p. 54-64, 2019. 